\title{
Socio-Psychological factors associated with child sexual abuse: A study of Lusaka Central Prison Child sexual abuse convicts
}

\author{
Zowe Tembo, ${ }^{1}$ Dabbie Nabuzoka, ${ }^{2}$ Paul Ravi ${ }^{3}$ \\ ${ }^{1}$ University of Zambia, School of Medicine, Department Of Psychiatry, P.O. Box 50110, Lusaka, Zambia. \\ ${ }^{2}$ Ministry of Home affairs, independence avenue, P.O. Box 50997 \\ ${ }^{3}$ Lusaka Central Prison, Chimbokaila Prison. \\ Corresponding Author: \\ University of Zambia, School of Medicine, Department of Psychiatry, P.O. Box 50110, Lusaka, Zambia. \\ Phone Number: 0977-846926; | E-mail: tembozowe@gmail.com | Email: musondalyna@yahoo.co.uk
}

\begin{abstract}
Objective and study design: with the view of examining the socio-psychological factors associated with child sexual abuse among child sexual abuse convicts, a study was conducted in Lusaka, the capital city of Zambia at Lusaka Central Prison also commonly known as Chimbokaila prison between January 2015 - July 2017. The scientific objectives of this study were to identify the background characteristics of convicts who are in jail for child sexual offenses; to establish the psychological factors associated with child sexual abuse among convicts; to explore the social correlates associated with child sexual abuse among convicts; to explore the social correlates associated with child sexual abuse among convicts and to establish the relationship between experiences of convicts in prison and behavioral intensions with regards to child sexual re-offending. 30 male child sexual abuse convicts were assessed for personality disorders and were interviewed to realize some of the social factors that may be associated with child sexual abuse.
\end{abstract}

\section{Results:}

Results of the DSMI IV criteria checklist showed that 24 respondents did not have a personality disorder while 6 respondents had a personality disorder. From the Minnesota Multiphasic Personality inventory 4 (MMPI- IV) showed that 10 participants had a personality disorder, while 20 participants did not have a personality disorder.

Results obtained from social correlates associated with child sexual abuse were: misleading physical appearances and substancemisuse. With regards to marital status, there was no statistical relationship between child sexual abuse and marital status. It was also found that there is no statistical relationship between child sexual abuse and Alcohol consumption.
It was also found that the respondents who took alcohol before imprisonment were more than those that did not. Most child sexual perpetrators were not sexually abused as children, those who were sexually abused as children were very few Percent and frequency distribution of Respondents by age group was; age group 25-30 recordedc the highest frequency of $36.7 \%$, followed by age group of 20 25 with $23.3 \%$. Percent and frequency distribution of the respondents by marital status; of the total respondents 40 percent $(n=12)$ were single and 46.7 percent $(n=14)$ were married, divorced participants and others had an equal share of percentage at 6.7 percent $(\mathrm{n}=2)$.

Conclusion: Put together the results suggest that the majority of participants did not have a personality disorder, in regards to Psychological factors that may be associated with child sexual abuse. Whereas a lot of common themes (most participants abused alcohol before imprisonment, were physically abused and not sexually abused in their childhood) were realized for social factors that may be associated with child sexual abuse, However for background characteristics it was found that most child sexual abusers were within their mid twenties and most of them were single with a primary level of education as the highest level of education obtained by most participants.

Keywords: convicts, child sexual abuse, DSM IV criteria checklist, Minnesota Multiphasic personality inventory 4(MMPI_IV).

\section{BACKGROUND}

\section{Introduction and literature review}

Sexual assault occurs in all cultures and it occurs at all levels of society. Global data suggests that one woman in every five has suffered an attempted or completed rape by an intimate partner during her lifetime. Sexual assault takes place within a variety 
of settings, including the home, the workplace, schools and in the community (Malawian Ministry of Health, 2012). Global estimates show that $13 \%$ women and $3 \%$ of men worldwide report sexual assault in their lifetime. Most sexual abuse offenders are acquainted with their victims, approximately 30 percent are relatives of the child, most often brothers, fathers uncles or cousins, around 60 $\%$ are other acquaintances such as friends of the family, baby sitters or neighbors, strangers are the offenders in approximately $10 \%$ of child sexual abuse cases. Most child sexual abuse is committed by men, studies show that women commit $14 \%$ to $40 \%$ of offenses reported against boys and $6 \%$ of offenses reported against girls.

However, th e prevalence of child sexual abuse in Africa is compounded by other factors such as cultural myths. One common myth present in most African countries is the virgin cleansing myth that asserts that sexual intercourse with a virgin will cure a man of HIV or AIDS but the actual causes of the child sexual abuse are not known.

\section{Problem statement}

There are a lot of people serving time in prisons as a result of child sexual abuse, some of whom have repeatedly sexually abused children. Despite the stiff punishment associated with child sexual abuse, new cases of child sexual abuse are still recorded which is indicative of certain factors beyond the social world that leads to the commitment of such crimes.

There is little knowledge and literature undertaken in Zambia amongst child sexual abuse convicts on weather child sexual abuse is a Psychological problem or it is a complex interaction of psychological factors and the social environment that leads to the commitment of such acts against children. Generally, there is no adequate literature on the topic child sexual abuse, specifically on the topic of social and psychological factors associated with child sexual abuse in Africa and Zambia victim or very close relations to the child, this leaves most child sexual abuse cases unreported.

Little is known about the child sexual perpetrators themselves in terms of actual causes of child sexual abuse or factors that may be associated with the vise of child sexual abuse. For this reason, the researcher took an interest in conducting this research so as to contribute to literature and to also fill in the gaps that exist in research concerning the topic of child sexual abuse.

\section{MATERIALS AND METHOD}

This study used both qualitative and quantitative data collection methods, in-depth interviews and semi structured interviews were used to collect data.. In-depth interviews were used to collect data from the key informants (the prisoners). Interviews were conducted on a one to one basis with participants (child sexual abuse convicts) in an open room. The researcher sat down on a chair facing each participant and interviews were conducted at different times for each participant.

The researcher gave each participant a demographic questionnaire to complete by themselves at the time of their interview. Where the respondent was not literate, the questionnaire was administered in an interview format by the researcher.

Upon completion, the Minnesota multiphasic personality inventory -2 ( Adult interpretive system version 4) was given to the respondents to be completed individually, to those participants who were able to read and write, for those who could not, the researcher assisted in administering the tool in interview form to assess personality disorders . Therefore, this tool was administered either through self- completion by the respondents or by interviewing the participants by the researcher disorders based on the DSM - IV -TR criteria for general personality disorders.

The researcher administered the DSM-IV-TR Criteria checklist on each participant, to assess personality disorders for both literate and illiterate participants, as to whether they exhibited any of the symptoms read to them by the researcher that were contained in the DSM-IV-TR criteria. Then in-depth interviews were conducted on a one to one basis , using- structured questionnaire with open ended questions to establish the relationship between experiences of convicts in prison and behavioral intentions with regards to child sexual reoffending after serving their jail sentence. These interviews were collected by the researcher in form of note taking.

The demographic questionnaire for both male and female participants comprised of seven items. the questionnaire that was assessing the effect of imprisonment on the behavior of convicts with regards to child sexual reoffending only contained one section and only comprised of 8 items. The questionnaire that was assessing social factors comprised of 10 items. It required them to fill in basic details of age, sex, marital status, highest 
level of education attained, religious affiliation.

Using purposive sampling method, method, the present study examined the social and psychological factors that may be associated with child sexual abuse among a population of child sexual abuse convicts a Lusaka Central Prison.

Four specific objectives guided the study ; to identify the background characteristics of convicts who are in jail for child sexual offenses ; to establish the psychological factors associated with child sexual abuse among convicts; to explore the social correlates associated with child sexual abuse among convicts and to establish the relationship between experiences of convicts in prison and behavioral intentions with regards to child sexual re- offending .

The study enrolled 30 participants; 29 male and 1 female participant in the data collection process. The psychological factors ( personality disorder) was assessed using a semi structured questionnaire and to establish the relationship between experiences of convicts in prison and behavioral intentions with regards to child sexual reoffending after saving their jail sentence. the DSMI-IV criteria checklist showed that 24 respondents did not have a personality disorder while 6 respondents had a personality disorder , Minnesota Multiphasic personality inventory 4 (MMPI-IV) showed that 10 participants had a personality disorder while 20 participants did not have a personality disorder. From the third specific objective of exploring social correlates associated with child sexual abuse, it was found that common themes to how respondents found themselves in prison were misleading physical appearances and substance misuse. As regards to marital status, there was no statistical relationship between child sexual abuse and marital status. It was also found that there is no statistical relationship between child sexual abuse and alcohol consumption. It was also found that the respondents who took alcohol before imprisonment were more than those that did not. Most child sexual perpetrators were not sexually abused as children, those who were sexually abused as children were very few offending scenarios. The potential victim is selected based on their vulnerability and accessibility and also because the offender is motivated by seeing an opportunity to offend without getting caught. This implies that the marital status of the perpetrator does not influence their action ., because the highest frequency was that of married men $n=14(46.7 \%)$, who in normal instances would be expected to have been the least because they have a sexual partner. As away of knowing whether the respondents had a formal education level, it was observed that the majority of the respondents reported that they had gone up to primary level of education.

\section{MAIN STUDY FINDINGS}

The percent and frequency distribution of the respondents by marital status of the total respondents were single and 46.7 percent were married, divorced participants 46.7 percent were married, divorced participants and others had an equal share of percentage at 6.7 percent respectively. Distribution of the respondents by level of education was 60 percent $(n=18)$ of the total respondents, their highest educational level was primary education, this was followed by those reporting that they had reached up to secondary level with a percentage 33.3 percent $(n=10)$. Respondents were probed to find out whether or not they used to take alcohol before imprisonment $\mathrm{n}=19,63.3$ percent reported that, they consumed alcohol before being imprisoned and $n=11,36.7$ percent said they did not drink alcohol before imprisonment. Respondents were asked to find out, if they were sexually abused as a child or not, $n=26,78$ percent reported that they were not sexually abused as a child, and $n=4,22$ percent reported that they were sexually abused as children. The DSM-IV-TR criteria (checklist) were administered among respondents to find out if they had a personality disorder or not. The findings showed that six (6) participants had a personality disorder and 24 respondents did not have a personality disorder.

The MMPI was administered among participants to find out if they had a personality disorder or not. From the MMPI-2, it was found that 7( 22\%) participants only were diagnosed with Hs Hypochondriasis, 23(78\%) participants only had D depression , 17 (56\%) had Hy conversion Hysteria participants only, 10 (33\%) participants were pd Psychopathic deviate , 27 (89\%) participants had Ma Hypomania and 17( 56\%) participants were Si Social introverts.

Upon asking participants to tell me about how they found themselves in prison, the most common themes that were arrived at were misleading physical appearances, being accused as a result of injustice, due to substance misuse ( such as alcohol, dagga ), ignorance 
towards real age of a child/ girlfriend. Respondent's responses towards the question that stated: what really made you engage in intercourse with a child? Were numerous in comparison to other questions asked, the common themes that were arrived at were self doubt/ poor self esteem, inappropriate dress cord by the victim, substance misuse (alcohol, Dagga), traditional beliefs, rituals for wealth acquisition, healing and not aging fast, incorrect thinking, (entertaining inappropriate thoughts, misleading physical appearances, influence from evil spirits, denial (I did not do it, I was just accused).

\section{DISCUSSION AND MAIN FINDINGS}

Identifying the background characteristics of convicts who are in jail for child sexual offenses

Upon identifying the background characteristics of convicts who are in jail for child sexual abuse it was found that most child sexual abuse convicts who were convicted for child sexual abuse at Lusaka Central Prison were male, at the female prison section only one female was identified.

This was similar to the findings of ( Collins - Vezin et al .,2013) that showed that most child sexual abuse is committed by men, studies show that women commit $14 \%$ to $40 \%$ of offenses reported against boys and $6 \%$ of offenses reported against girls . this implies that most sexual offenses reported against boys and $6 \%$ of offenses reported against girls . this implies that most sexual offenses are committed by men and women . also, these findings were similar to those of Westcott ( 1984), who described 18 cases of child sexual abuse at cape Town Hospital . Victims ranged in age from two to 12 years and the majority ( 80 percent) was female. The research study consisted of a sample of thirty participants, it was observed that the highest age range recorded was twenty five to thirty years, the least age of participants were between thirty five to forty years of age.

With regards to marital status, it was noted that the highest number of participants were married and the least number of participants were divorced and others. This was similar to (Ward and Beach, 2006) findings, who stated that often the offender starts with identifying the potential victim well before committing a sexual offense, they use sexual fantasies to rehearse possible least number of respondents who took part in this study had attained a level of education in college ( diploma). However, it was found that the respondents who took alcohol before imprisonment were more than those who did not. This implies that the most child sexual convicts took alcohol before imprisonment, this was similar to a study done by Wang and Dark ( 1988) which recorded most deaths of abused children were recorded due to defilement by drunk male adults, the number of reported and substantiated victims of child maltreatment during 1995,1996 and 1997; a breakdown by type of maltreatment ; and the number of confirmed fatalities resulting from child sexual abuse. Child sexual abuse constituted $7 \%$ of reported cases and $8 \%$ of substantiated cases from alcoholics.

With regards to the distribution of respondents by how often they took alcohol before conviction, it was observed that over half the respondents took alcohol at least once a month. With regards to whether the respondents were sexually abused as a child, it was found that the majority of respondents stated that they were not sexually abused as a child and only a few participants reported to being as children . however, this was in contrast with the findings of (Marshall and Barbaree, 1990) who found an association between those who were abused as children to sexually abuse a child as they grow up. Specificallly, this theory suggests that individuals experiencing developmentally adverse events ( e.g poor parenting, inconsistent and harsh discipline, physical and sexual abuse ) are likely to exhibit distorted internal working models of relationships, especially with reference to sex and aggression, resulting in poor social and self-regulation skills from an early age.

From the chi square test, it was found that there is no relationship between child sexual abuse and marital status. It was also found that there is no relationship between child sexual abuse and alcohol consumption.

Establishing the Psychological factors associated with child sexual abuse among convicts

The researcher found that the Psychological factors associated with child sexual abuse by the use of a DSMI_IV_TR criteria checklist) were that 24 respondents did not have a personality disorder while 6 respondents had a personality disorder. However, these findings were in contrast with the findings of ( Hall and Hirschman 1992 ) that stated that based on four components that may contribute to the occurrence of child sexual abuse among perpetrators are personality problems, physiological sexual arousal, inaccurate cognitions that justify sexual aggression and affective dyscontrol . From the study, it was found that most participants depicted inaccurate cognitions and personality problems to be key factors that may be associated with child sexual abuse. The first component being personality problems are representative of long term vulnerability factors (trait factors), by implication, this means that personality deficits are the seeds that 
produce vulnerabilities to sexually abuse children. The last three components are considered primarily as state and situation dependant ( state factors ) ( ward and Beech 2006).

The Minnesota Multiphasic Personality inventory 4 (MMPI_IV), The MMPI was administered among participants to find out if they had a personality disorder or not. From the MMPI-2, It was found that 7 ( $22 \%$ ) participants only were diagnosed with Hs Hypochondriasis, 23 (78\%) participants only had D depression, 17( 56\%) had Hy conversion Hysteria participants only, 10 ( $33 \%)$ participants were $\mathrm{pd}$ psychopathic deviate, 27 (89\%) participants were Mf, Masculine, 13 ( $44 \%$ ) participants had a pa paranoid personality disorder, 7 (22\%) participants had pt Psychasthenia, 3(11\%) participants had Schizophrenia $3(11 \%)$ participants had Ma Hypomania and 17 (56\%) participants had Ma Hypomania and 17 (56\%) participants were Si Social introverts .However, these findings were in contrast with the findings of ( Hall and Hirschman 1992) that stated that based on four components that may contribute to the occurrence of child sexual abuse among perpetrators are personality problems.

\section{Social correlates associated with child sexual abuse among convicts}

It was found that, respondents views about defilement was that defilement is having canal knowledge with a minor below the age of 16, and having sexual intercourse by force with a child. With regards to how participants found themselves in prison. It was noted that most respondents stated that misleading physical appearances, being accused as a result of injustice, due to substance misuse (such as alcohol, dagga), ignorance towards real age of child/girlfriend were some common themes.

With regards to what really made you engage in intercourse with a child, it was found that: self doubt/ poor self esteem, inappropriate dress cord by the victim, substance misuse, (alcohol and dagga), traditional beliefs, rituals for wealth, acquisition, healing and not aging fast, incorrect thinking, entertaining inappropriate thoughts, misleading physical appearances, influence from evil spirits, denial (I did not do it, I was just accused) were the common themes that were arrived at. However, these findings were similar to some findings of (Ward and Hudson 1998) that showed that those who lack social regulation are likely to sexually offend. In adolescence especially, lack of effective social and self regulation skills makes it more likely that attempted relationships with women are more likely to be turned down, leading to low self esteem. this may eventually fuel intensity of sexual desire hence sexual offending becomes more probable, general level of anti- sociality, contextual antecedents to violence such as criminogenic needs, deviant social networks (i.e. drug trafficking, drug abuse, alcohol abuse, rape, gangs, dagga abuse) and lack of positive social supports. It was found that participants responses towards how their love life was before they were convicted were: married, single, in a relationship, in numerous relationships, lack of interest in women, was in a relationship, in numerous relationships, lack of interest in women, was in a relationship with the child as the most common themes. This was in contrast with the findings of (Ward and Beech, 2006) that stated that child sexual perpetrators come from all background, age socio economic and ethnic groups. In most cases, the offender starts with identifying the potential victim well before committing a sexual offense they use sexual fantasies to rehearse possible offending scenarios. The potential victim is selected based on their vulnerability and accessibility and also because the offender is motivated by seeing an opportunity to offend without getting caught. In terms of how respondents perceived themselves in terms of attraction to the opposite sex, it was found that the following common themes were arrived at: attractive (high self esteem), unattractive and the use of alternative ways to attract women.

Upon asking participants who the child was to them, most common responses were: she was my girlfriend. This was similar with some of the findings by (Putnam, 2003) that stated that most sexual abuse offenders are acquainted with their victims , approximately 30 percent are relatives of the child,most often brothers, fathers, uncles or cousins , around $60 \%$ are other acquaintances such as friends of the family, baby sitters or neighbors , strangers are the offenders in approximately $10 \%$ of child sexual abuse cases .similarly, findings of Jaffe and Roux ( 1988), who examined 88 Children, s Hospital. Of these 88 children, $90 \%$ were female and most were in the age group of four to six year old. In 57 percent of cases, the perpetrator was known to the victim. The largest category of perpetrator (16) was that of a neighbor, followed by father (14) .

It was found that participants responses towards the intentions they had with the child were, no serious intentions they had with the child were, no serious intentions, dating, in a relationship and marriage. However, it was recorded that the most common form of sexual abuse was vaginal sex (penetrative sex).

It was however found that that what made the child to be more susceptible to being sexually abused was that 
the child was alone on the streets , ( away from home, she was a neighbor, she lived with both her parents , ( only that they were not around at the time it happened). These findings were similar to those of Westcott (1984), who described 18 cases of child sexual abuse at a Cape Town Hospital. Victims ranged in age from 2 to 12 years and the majority ( 80 percent) was female. In over half of the cases, the offender was a relative, a neighbor or a friend of the family. With regards to respondents upbringing, in terms of childhood growing up (tough childhood), guardians/parents were very harsh, aggressive, physical punishment, no food, hard jobs, beatings. These findings were similar to Marshall and Barbaree (1990) who specifically stated that individuals experiencing developmentally adverse events ( e.g poor parenting, inconsistent and harsh discipline, physical and sexual abuse) are likely to exhibit distorted internal working models of relationships, especially with reference to sex and aggression, resulting in poor social and self - regulation skills from an early age.

However, it also found that participants responses as to whether their parents, guardians provided them with adequate care was that their parents provided them with all the necessities of life, life changed after father's death ,started living a very tough life, led a very tough life when growing up, experienced a lot of physical abuse and verbal abuse. In contrast with Hall and Hirschman (1992), it was however, noted that some respondents who grew up with both parents and were provided with all the vital necessities of life from childhood to adulthood also reported to having abused a child sexually.

It was also found that common themes recorded from participants responses to whether they observed anyone from their family being abused sexually or physically were that yes, especially female relatives and no never experienced any. These findings were similar to the Pathways Model which suggested that there are multiple pathways leading to the sexual abuse of a child. Each pathway involves a core set of dysfunctional psychological mechanisms. In this sense, mechanisms are psychological processes that cause specific outcomes, effects or clinical phenomena. These mechanisms constitute vulnerability factors and are influenced by distal and proximal factors, including learning events, biological, cultural and environmental factors.

As a way of knowing if there were any events or anything that made it difficult to have sexual relationships with adult males/females, it was found that common themes recorded were "nothing makes it difficult for me to have adult sexual relationships".

Relationships between experiences of convicts in prison and behavioral intentions with regards to child sexual reoffending

From the fourth specific objective, in trying to understand relationships between experiences of convicts in prison and behavioral intentions with regards to child sexual reoffending : it was found that participants responses on what they understood by imprisonment were it's a place where they keep wrong doers for committing offense.

With regards to respondents opinions on whether they think imprisonment had been seen as a suitable treatment measure for child sexual abuse among convicts over the years, it was found that, some common themes were : yes prison is a good treatment measure, prisoners learn new crimes from the prison environments, others learn others do not,yes prison changes people because it's a bad place to live ( very bad living conditions).

Upon asking participants to whether they think imprisonment has shown to be an effective treatment measure for child sexual offense, it was found that, common themes arrived at from respondents were it's a very effective treatment measure, for child sexual offense, yes it's a very effective treatment measure.

Common themes arrived at from respondents in trying to find out how many convicts have been rearrested for child sexual offenses after being released from prison in the past years were: not seen any, because of the many years attached to the case of defilement and also most convicts are taken to Kabwe Central Prison, yes for minor cases such as theft, fights, that attract less periods of time in jail such as 3-6 months but defilement cases are rare. Some of the responses given by respondents upon asked about some of the experiences with being in prison and some of the reasons to why prisoners reoffend after serving their jail sentences were found to be financial hardships, of life on the outside, ,criminal ideas are learnt and shared inside prison,, some prisoners adapt to prison life and keep on reoffending, where to start from( financial capital) after prison life and many years spent in prison. It was found that some common themes recorded from the question "what do you think are some challenges faced with imprisonment been an only mode of treatment for child sexual abusers?"

\section{CONCLUSION}

This study was conducted to examine the SocioPsychological factors associated with child sexual abuse among convicts at Lusaka Central Prison. Any sexual act against a minior using force or manipulation is alluded to as sexual abuse or defilement . despite 
the stiff punishment associated with child sexual abuse in Zambia as well as other countries, new cases of child sexual abuse are still recorded which is indicative of certain factors beyond the social world that leads to the commitment of such crimes . For this reason, four research questions were designed that served as a guide to the whole research process.

\section{ACKNOWLEDGEMENT}

I would like to pass my sincere gratitude to the: University of Zambia DRGS School of Medicine Department of Psychiatry, the Research Supervisor Prof D. Nabuzoka, and Dr Paul, the Lusaka Central Prison Management, the convicts at Lusaka Central Prison, Miss T. Tembo, Family members and friends for making this study a reality and success.

\section{REFERENCES}

Abel, G.G., Lawry, S.S., Karlstrom, E., Osborn, C.A., \& Gillespie, C.F. (1994) Screening, 105-122.

Abel, G.G., Osborn, C., Anthony, D., and Gardos, P. (1992) Current treatments of paraphiliacs: Annual Review of Sex Research, 225-290.

Available:http://www.americanhumane.org/ children/stop-child-abuse/fact-sheets/childsexual-abuse.html?referrer=https://www. google.com/ among sexual offenders(24 Aug 2001).

APA, (1994 ) Summary of practice: Relevant changes to the DSM- IV-TR, psycho med.

APA, (2000) Summary of practice : Relevant changes to the DSM-IV-TR, psycho med.

Araji, S. and Finkelhor, D. (1986) Abusers: A review of the research, $A$ Sourcebook on Child Sexual Abuse, Sage, Newbury Park, CA.

Blaike, N. (2000) Designing Social Research, Cambridge: Polity Press internal .

Blaike, N. (2010) Approaches to Social Enquiry, Cambridge, England : U.K., Polity Press.

Braun, V. and Clarke, V. (2006) Using thematic analysis in psychology: Qualitative Research in Psychology, vol.3, pp. 77-101.

Briere, J. and Runtz, M. (1989) The Trauma Symptom Checklist (TSC-33): Early data on a new scale, Journal of Interpersonal Violence, vol. 4, pp. 151-163.

Briere, J. and Malamuth, N.M. (1983) Self-reported likelihood of sexually aggressive behavior: Attitudinal versus sexual explanations, Joumal of Research in Personality, vol.17, 31 5- 323
Briere, J., Evans, D., Runtz, M. and Wall, T. (1988) Symptomatology in men who were molested as children: A comparison study, American Journal of Orthopsychiatry, vol.58 4 57-461 Bryant, A. and Charmaz, K. (2007) The SAGE Handbook of Grounded Theory, London,England, U.K: Sage Publications Ltd.

Bryman, A. (2008) Social Research Methods, Oxford: England, UK, Oxford University Press.

Butcher, J.N., Dahlstrom W.G, Graham J.R, Tellegen A. M, Kreammer ,B., (1989) The Minnesota Multiphasic PersonalityInventory-2 (MMPI-2) Manual for Administration and Scoring. Minneapolis, MN: University of Minneapolis Press.

Byman, A. (2012) Social research method, Oxford: Oxford University Press

Collin-Vézina, D., Daigneault, I and Hébert, M. (2013) Lessons learned from child sexual abuse research: prevalence, outcomes, and preventive strategies, Child and Adolescent Psychiatry and Mental Health.

Finkelhor, D. and Ormrod, R. (2001) Crimes against children by babysitters: Juvenile.

Finkelhor, D. (1994) The international epidemiology of child sexual abuse: In Child Abuse and neglect.

Finkelhor, D., Williams, L.M., and Burns, N. (1988) Nursery crimes: Sexual abuse in day care, Newbury Park, CA; Sage Publication.

Finkhelor, D., David, N. (1984) Child Sexual Abuse: New Theory and Research, New York: Free press.

Fraser, G. and Kilbride, P. (1980) Child abuse and Neglect - rare, but perhaps increasing: phenomenon among the Samia of Kenya, Child Abuse and Neglect, vol.4 pp .227-232.

Fuller, A.K. (1986) Child molestation and pedophilia: An overview for the physician, JAMA, 602-606.

Hall, G.C.N. and Hirschman, R. (1992) Sexual aggression against children: A conceptual perspective of etiology, Criminal Justice and Behaviour, vol. 2

Hanson, R.K. and Harris, A.J.R. (2001) A structures approach to evaluating change.

Lalor, K (2005) Child Sexual Abuse in Sub-Saharan Africa: Child Protection implications for Development Policy Makers and Practitioners, Development Research Briefings Centre for Development Studies: Dublin, University of Dublin.

Lampe, A. (2002) Prevalence of sexual and physical abuse and emotional neglect in Europe: Zeitschrift für Psychosomatische Medizin, pp. 370-380. 
Laws, D.R. , Marshall, W.L. (2003) A brief history of behavioral and cognitive behavioral approaches to sex offenders: Part 1 Early developments, Sexual Abuse: A Journal of Research and Treatment, vol.2, pp 75-92. Jaffe, A.M. and Roux.k. (1988) Sexual Abuse of Children: A hospital based study',South African Medical Journal, no.74, pp. 65 - 69

Levett, A. (1989) A study of childhood sexual abuse among South African university women students: South African Journal of Psychology, vol.3, pp. 122-129.

Loening, W. (1981) Child abuse among the Zulus: a people in cultural transition, Child Abuse and Neglect, pp 3-7.

Madu, S.N. and Peltzer, K. (2000) Risk factors and child sexual abuse among secondary school students in the Northern Province (South Africa): Child Abuse and Neglect, pp. 259-268.
Madu, S.N. and Peltzer, K. (2001) Prevalence and patterns of child sexual abuse and victimperpetrator relationship among secondary school students in the Northern Province, South Africa: Archives of Sexual Behaviour, pp. 311-321.

Malawian Ministry of Health (2012) Guidelines for Provision of Comprehensive Services for Survivors of Physical and Sexual Violence at Health Facilities in Malawi, One Stop Centres.

Marshall, W.L., Barbaree, H.E., and Eccles, A. (1991) Early onset and deviant sexuality in child molesters: Journal of Interpersonal Violence, vol.3 pp. 323-336.

Miles, M. B. and Huberman, A.M. (1994) Qualitative Data Analysis, London: Sage.

Moller .A, Bier-Weiss I. (1995) The pedophilic offender: an attempt at perpetrator typology, Psychiatric Prax, pp. 24-26. 
TABLES AND FIGURES FOR THE STUDY ANALYSIS

Description of Background Characteristics of respondents

Figure 1: Percent and Frequency Distribution of Respondents by age group of participants

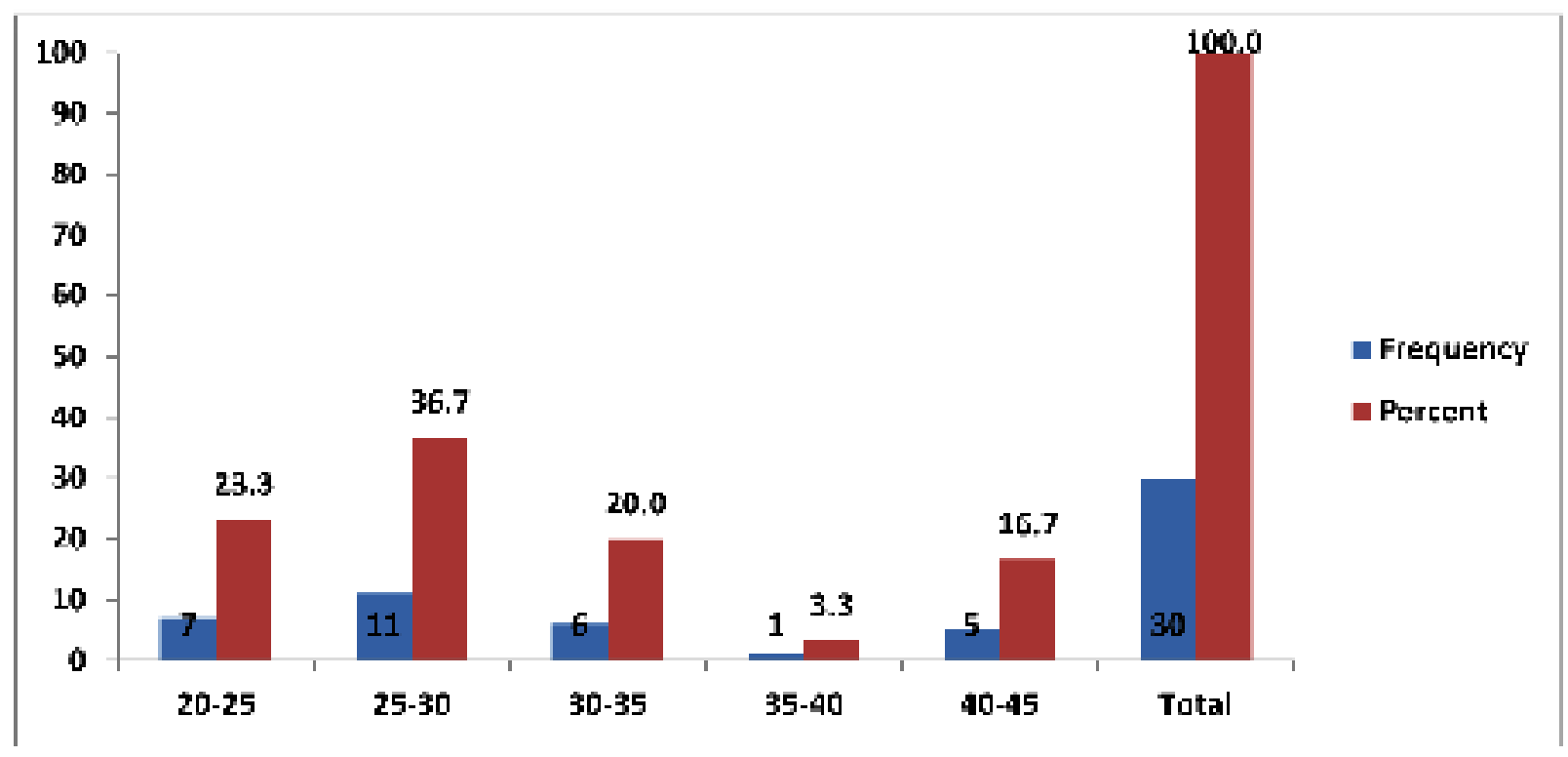

Figure 2: Distribution of respondents who were either sexually abused as a child or Not

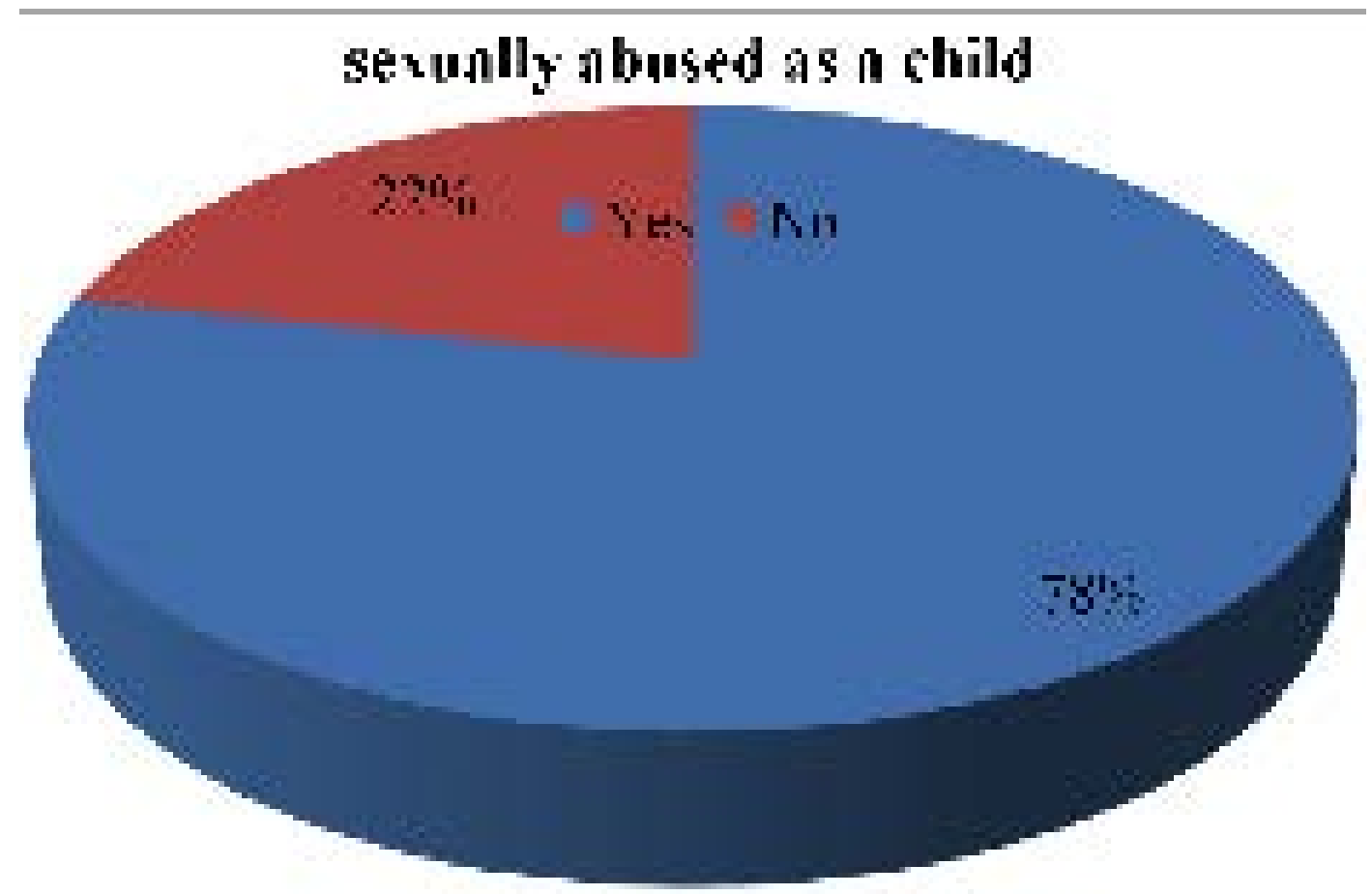


Table 1: Psychological factors associated with child sexual abuse (assessing personality disorders using the DSM- IV-TR criteria)

\begin{tabular}{|c|c|c|}
\hline $\begin{array}{l}\text { Number of participants with a } \\
\text { personality disorder }\end{array}$ & $\begin{array}{l}\text { Number of participants without } \\
\text { a personality disorder }\end{array}$ & Total number of participants \\
\hline 6 & 24 & 30 \\
\hline
\end{tabular}

Figure 3: Assessing Personality Disorder using the Minnesota Multiphasic Personality Inventory 4 (MMPI- IV).

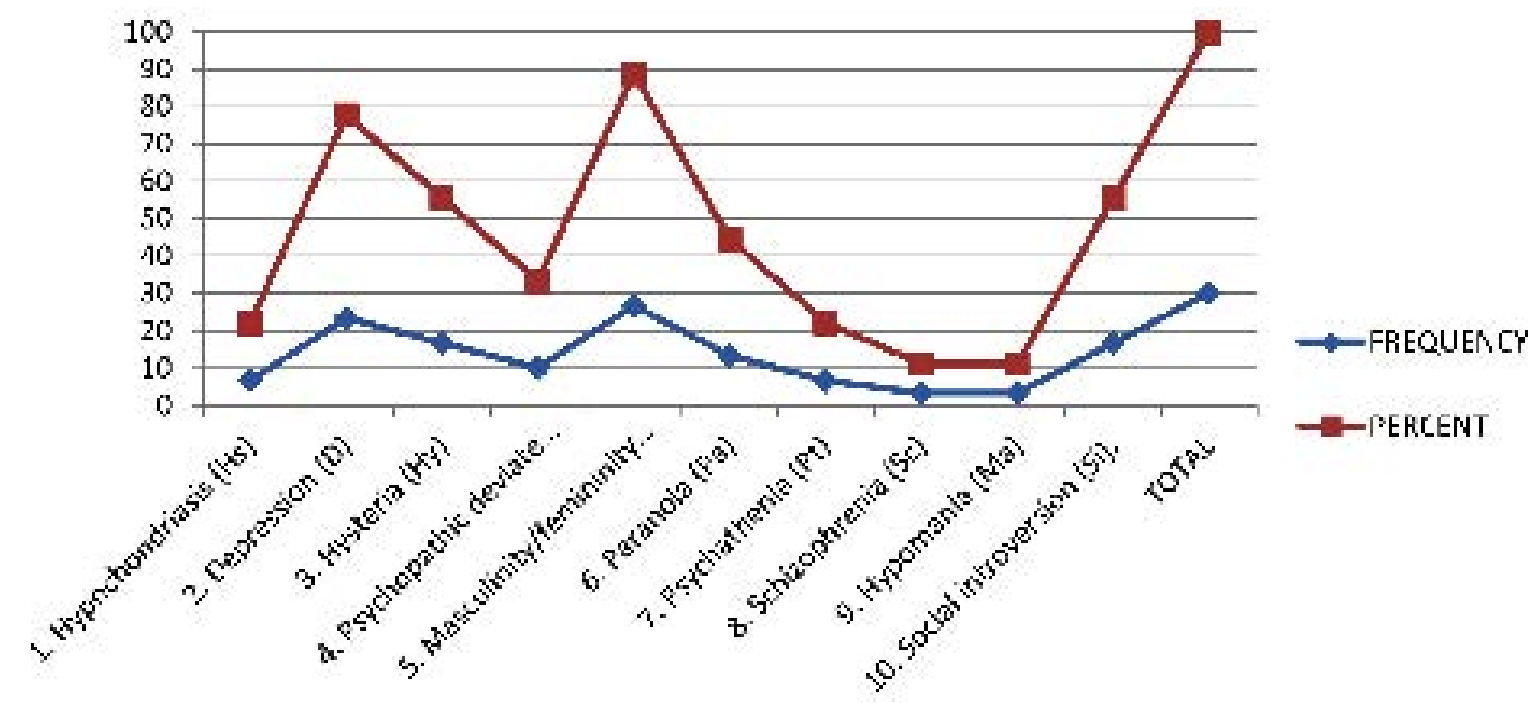

Psychological factors associated with child sexual abuse (assessing personality disorders using the MMPI). (5 = Mf Masculine). 